\title{
Status and Design of Digital Oilfield
}

\author{
Xu Xiaohong ${ }^{1}$,Tian $\mathrm{Hu}^{1}$ \\ ${ }^{1}$ School of Geosciences, Yangtze University, JingZhou \\ China 434023 \\ E-mail:tianhu2010@126.com
}

\author{
Fu Jilin ${ }^{2}$,Sun Zhihua ${ }^{2}, \mathrm{Xu} \mathrm{Xin}{ }^{3}$ \\ ${ }^{2}$ CNPC Niger Petroleum S.A. Niamey Niger \\ ${ }^{3}$ Iowa Wesleyan College,The United States of America
}

\begin{abstract}
At present, the global petroleum exploration and production enterprises are all faced with dual huge pressures which are to lower operating costs and improve labor productivity, but the appearance of digital oilfield let these companies find a silver lining. This paper expounds the difficulties that the domestic digital oilfield encountered in the design of construction, and combining with the actual need of the oil fields in the development of oil-gas exploration, especially discusses the common problems in the construction of current digital oilfield and analyzes the existing oilfield technology and the development needs, finally, it put forwards feasible solutions.
\end{abstract}

\section{Keywords-Component GIS;Digital oilfield;Database}

\section{INTRODUCTION}

The production and management of oilfield development involves complex information at multiple aspects and levels ${ }^{[1]}$. such as the geographical distribution of the oil wells, casing programme, performance of oil well production, geological features of the reservoir. These information shows the feature of the typical three-dimensional spatial distribution and data diversity. There will be lots of data generated in the every part of oil field exploration, development and management, many of which are extremely large and various in data size as well as in categories, so it is hard for us to use the traditional way to effectively conduct information management and retrieval on data system, and more important is that the old system is difficult to reflect the various objects involved in oilfield and the related information of the spatial distribution relationships. In order to improve the level of data management and application efficiency, we must establish a unified data management system, at the same time, all the oil production, research and business areas need the support of powerful IT platform. These needs are becoming and more and more desperate, complex, and demanding. Only the advanced technologies (GIS) of building a comprehensive digital oilfield will the needs ultimately be met $^{[2] .}$ Therefore, it appears necessary for us to use GIS to in management, by combining data from geographic information and oilfield, based on the map of oilfield as a carrier, we can do a variety of inquiries, statistics and analysis, providing a scientific basis for oil field development and management in planning, judgment and decision-making.

\section{WHAT IS THE DIGITAL OILFIELD?}

Digital oilfield is a Digital Earth technology-oriented, oilfield entities targeted, geospatial coordinate based, with integrating the multi-resolution, magnanimous data and various data; it can be multi-dimensional expressed by multimedia and virtual technology; it is a technology system with features of spatialization, digitization, networking, intelligentizing and visualization ${ }^{[3]}$. It is a technology system that the digital Earth technology serves as a backbone in achieving comprehensive informatization of the oilfield entities. The digital oil field is a subsystem of the Digital Earth, a digital virtual body in the exploration and development, production and operation process of the oilfield and gas geological features. it will be constantly improved in the whole life cycle of oilfield entities. By interacting with the virtual body, people can deepen the understanding of the oilfield geological features, optimizing the process of exploration and development and enhancing the ability of the management, thus winning the maximum economic benefit for oilfield enterprise ${ }^{4-5]}$.

At present, the domestic digital oil field has been in rapid development. Da Qing Oilfield Company is showing his leading role, while the Xinjiang Oilfield, Tarim Oilfield also establish the digital oilfield information systems correspondingly. Although Da Qing Oilfield Company is already a domestic leading position, there is still a big gap comparing with the international oil companies. Domestic digital oilfield construction is still in its infancy, with insurmountable. The extravagant hope of finishing it at one stroke is unrealistic. Therefore, we must get down to prepare the ground, solving specific problems in the data resource development, the construction of application systems and information management.

\section{THE STATUS AND THE PROBLEMS OF THE DOMESTIC DIGITAL OILFIELD}

Although the major domestic oilfield companies have joined the army of the "digital oilfield" construction in various degree, played the banner of the digital oilfield construction, seen overall, the domestic digital oilfield construction still exists and nagged by some problems.

First, in the concept, different oilfield enterprises differ in the understanding of the digital oilfield in the actual implementation: in many places, some enterprises fan out from point to area, and exaggerate some minor 
issues in the digital oilfield, calling the office automation system as the completion of the digital oilfield. The opposite is also existed, some enterprises have conceived a large amount of theoretical systems, but impractical and impossible to start. In this regard, we must deepen the understanding of the concept of the digital oilfield, and make relevant planning to our own unit's reality ${ }^{[6]}$. Here, the main problems in the construction of the digital oilfield are in the following aspects:

1) The digital oilfield system is difficult to integrate with existing applications systems;

2) There exists problems of data standardization;

3) The coordination problem between the system as a decision-making support and the existing management system;

4) It is critical to implement the organizations of digital oilfield construction;

5) Computer network technology is unable to meet the huge amount of data transmission;

6) The security of data-sharing network.

\section{GIS PROVIDES TECHNICAL METHODS FOR THE DIGITAL OILFIELD}

As the methods of GIS technology in spatial data organization, management, analysis, display, etc., it is one of the necessary technology to solve the problems of the digital oilfield. Its content involves the aspects of digital oilfield in a variety of spatio-temporal data and thematic data collection, input, storage, retrieval, processing, and analysis, provides necessary information and knowledge support for the oilfield planning, management and decision-making.

Geographical information is the basis of the mapping of the oil industry, and the describing object is the Earth's underlying structure, the characteristic of lithology, physical properties, electrical properties, the emerging, reservoir and cover of the oil gas, all of which are built on the Geographic Information. The development of GIS's speed is very fast and its application will inevitably bring about the development of the digital oilfield technology. The application of GIS technology in oil field will conduct the management planning in the following aspects: management and exploration of oil exploration results planning and design; development and production management; real-time drilling simulation and wellbore data show; ground project management and project planning; virtual reality display of reservoir simulation and reservoir; the remaining oil and gas distribution show; management and calculation of the reserves of oil and gas fields; oilfield production analysis and decision-making ${ }^{[7]}$.

In order to achieve the various functions of the digital oilfield, without leaving a too large digital oilfield information system, we can use the component GIS to achieve the major functional blocks of the digital oilfield. The basic idea of the component GIS is to divide the major functional modules of GIS into a number of controls and each control performs different functions but integrates through the digital oilfield information system, shaping the final digital oilfield.
Although GIS is a key technology of the digital oilfield, the technical supporting basis of the spatial information services, but in the process of realizing the digital oilfield, GIS is still faced with certain challenges. In the oilfield construction process, while the amount of the data size and amount of information accumulated by the oilfield are growing bigger and bigger, the demand grows higher and higher on the network, thus making relying solely on GIS in constructing digital oilfield not satisfy the actual needs. Which in particularly requiring the rapid development of network technology, to achieve the large amount of data in the network of the need of the resource sharing, collaborative processing and intelligent decision-making environment.

\section{THE STRUCTURAL DESIGN OF THE DIGITAL OILFIELD}

The digital oilfield can be composed by the 8-class database in the following figure, which includes almost all the data information of oilfield in production management. With new data generating in the oilfield production, in this process, there, needs constantly update the database to meet the various departments. The professional types of data used in the process of their professional, can be also shared each other in the various professional real data, thus making the data sharing coming true.

The system is proposed to adopt B / S and C / S mixed-mode design, the advantages of the $\mathrm{B} / \mathrm{S}$ is that it can operate in any place without having to install any specific software. The expansion of the system is very easy, as long as the network exists, when a user name and password assigned by the system administrator, then you can use. B / S is to display the content, and the staff with general competence can conduct oilfield related information inquiries, and some simple arithmetic. While the C / S structure is used for all kinds of oil gas maps, editing and computing operations on the database of the digital oilfield. The digital oilfield structure is shown in Figure1.

\section{CONCLUSION}

In recent years, international oil price is soaring high, heating up the sensitive oil resources problem, and bring oil companies around the world unprecedented pressure and huge stimulus. Finding and occupying new oil resources and fully tap the efficient use of oil resources are placed in strategic issues in front of the oil companies and even the world. Digital oilfield technology will bring a ray of hope to solve these problems. So it can be expected in the coming years, the world's oil companies will continue to further vigorously promote the construction of the digital oilfield, which will effectively promote the digital oilfield technology to quickly go into maturity.

The digital oilfield is a huge infrastructure project, and it is an inevitable trend of the oilfield development and information technology, also the fatal road of the oil field development. Facing the practical application of the oil fields, fully researching the architecture model of the 
digital oilfield, combining a variety of field data, the composition and characteristics, the constructing of the digital oilfield under the back of GIS, is one of the greatest tasks nowadays.

\section{REFERENCE}

[1] Wu Xin Rong, GIS based information management system of oil field development[J]Journal of Jiang Han Petroleum Institute , 2004.6.26 (2) ; 151-152

[2] He Zhen Ming, Wu Xin Cai, He You Bing, etc. Based on the GIS platform based on digital oilfield[J]Journal of China University of Geosciences, 2010,5,35 (3) , 491-492

[3] Wang Quan, Daqing Oilfield Company Limited, information construction overall planning in 2003-2005, 2002
[4] He Sheng Hou, Mao Feng, Digital oil field, theory, design and Practice[M]Science Press 2001

[5] Li Jian Feng, etc., Digital oilfield[M]Chemical Industry Press, 2006

[6] Liu Xuefeng, He Zhen-ming,He Youbin. The Oil and Gas Exploration Aid Decision-making Based on GIS: Principles, Methods and Applications [M].Petroleum Industry Press, 2008. (in Chinese)

[7] J. M. Yarus T. C. Coburn. Geographic Information Systems in Petroleum Exploration and Development:An Introductory Essay

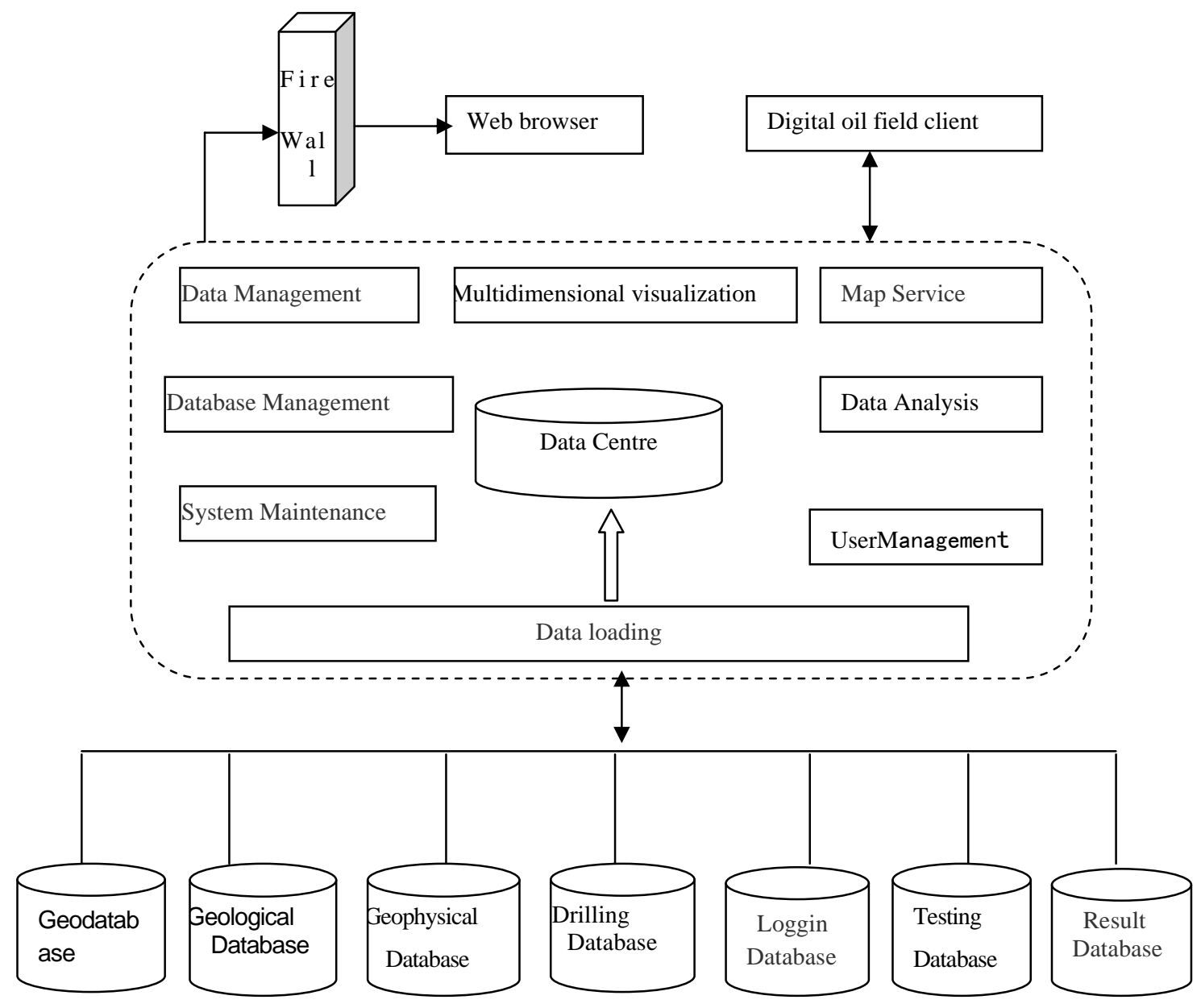

Figure 1: Digital oilfield structure model 